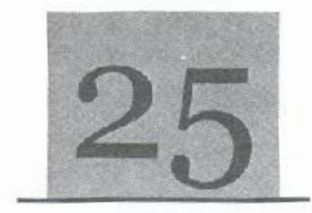

\title{
Screening of lactic acid bacteria from the gut of Chrysichthys nigrodigitatus for use as probiotics in aquaculture production
}

\author{
Ayo-Olalusi, C.I. / Oresegun, A. / Edah, B.
}

Abstract

Lactic acid bacteria (LAB) namely Lastobacilius plantarumi and L. pentosus were isolated from the gut of Chrysichthys nigrodigitatus and identified using Bergey s manul of determinative bacterialogy (APl-50 CHL, BioMerieux). They are beneficial and safe organisms that improve disturbances of the indigenous microflura and host's immune system. Gut removed from fish samples were dissected and divided into 3 regions: fore gut, mid gat and hind gut. Lactobacillus plantarum I and L. pentosus were isolated from these regions using MRS (de Man, Rogosa and Sharpe) agar and broih after suhsequent culture and sub culture to obtain discrete colonies. They were characterized as gram-positive, non-motile, catalase negaive and non-spomlating bacleria.

Keywords: Probiotics, Lactic acid bacteria. Chrysichthys nigrodigitatus, fish farming.

\section{Introduction}

Drobiotics are described as preparations of living microbial cells that, when ingested in high enough concentration, beneficially affect the host's health by improving the intestinal microbial balance (Fuller, 1989). Selection of probiotic strains is achieved by screening procedures for several characteristics such as inhibitory activities against several pathogens, resistance to gastric secretions, bile tolerance and growth in faecal material. They should resist processing and storage conditions and be alive and active even after gastrointestinal passage. They should be safe and impart benefits to the host ((Fuller, 1989; Havenaar et al., 1992a). Lactic acid bacteria are gram-positive, non-sporulating and catalase negative rods or cocci that ferment various carbohydrates mainly to lactate and acetate. Probiotics are lactic acid bacteria (LAB) characterized as Gram-positive, non-motile, non-spore forming bacteria, non pigmented (Hasan,and Frank, 2001), and catalase negative. The most commonly used organisms in probiotic preparations are lactic acid producing bacteria such as lactobacilli, streptococci, Bifidobacteria, Bacillus spp. and fungi like Sacharomyces cerevisiae, Sacharomyces boulardii and Asperyillus oryzae (Fuller, 1992). However, lactic acid bacteria (LAB) have attained major attention for probiotic activity and have generally been considered as good probiotic organisms (Saavedra, 2001; Sullivan et al., 1992).

The aim of the study was to screen lactic acid bacteria from the gut of Chrysichthys nigrodigitatus and classify them based on the morphological and biochemical characteristics.

Materials and Methods

Mxperimental fish for analysis: lish samples were collected from Lagos lagoon and transferred to the Nigerian Institute for Medical Rescarch laboratory within $1 \mathrm{hr}$. Twenty (20) samples of different sizes were selected. The length and weight of the fish were measured before dissection. The skin was then washed with $70 \%$ cthanol before opening the ventral surface with sterile scissors. The fish were dissected to remove the gut and divided into fore gut, mid gut and hind gut in other to determine where there is more concentration of probiotics in these regions. $1 \mathrm{~g}$ of intestine was taken from each fish sample and suspended in $9 \mathrm{ml}$ of stcrile saline diluents $(0.85 \% \mathrm{NaCl}$. The gut samples were homogenized in a blender using saline, scrially diluted and allowed to grow in MRS broth medium.

- Preparation of Media: The bacteria Lactobacillus spp. was isolated from fish gut by using modified MRS broth and MRS agar media. 52 grams of the media was suspended in one litter of distilled water each. They were mixed well, heated agitating frequently until complete dissolution of the medium. Each medium was dispensed in ad- 
equate containers and sterilized in autoclave at $121^{\circ} \mathrm{C}$ for 12 minutes. Additionally, $0.05 \%$ cysteine was added to MRS to improve the specificity of this medium for isolation of lactobacillus. The $\mathrm{pH}$ of the media was adjusted to 6.2 .

- Isolation of Bacteria: Lactohacillus was isolated from Chrysichthys nigrodigitatus by using MRS medium. One gram of each sample was dissolved into $100 \mathrm{ml}$ of MRS broth at $\mathrm{pH} 6.5$. After dissolving into MRS broth they were shaken homogenously and incubated at $37^{\circ} \mathrm{C}$ for $24 \mathrm{~h}$ in aerobic condition. The cultures were subjected to five subculture at $37^{\circ} \mathrm{C}$ under low $\mathrm{pH}(\mathrm{pH} 4.5)$ and anaerobic condition in the presence of $10 \% \mathrm{CO}_{2}$ to remove unwanted bacteria. After seven subcultures, the bacterial culture was streak onto MRS agar media at pH 4.8. Finally, the single colony of lactobacillus was isolated observing their colony morphology and some biochemical tests. (Gram staining, catalase, endospore and motility lest) and the eulture were maintained in MRS broth at pII 5.5.

- Biochemical test for LAB

- Grams staining - Heat fixed bacterial smear slide was placed on a staining rack stained with crystal violet for 1 minute, washed in tap water, cover with grams iodine for 1 minute, re-washed, decolourised by washing the slide briefly in acetone (2-3 seconds) 1 and counterstained for 10 minutes in Safranin. The smears were washed thoroughly with water and gentle air dried and observed under oil immersion.

- Methyl Red test (MR): Isolated lactic acid bacteria was inoculated with buffered glucose broth and incubated at $37^{\circ} \mathrm{C}$ for 48 hours. After incubation, a few drops of methyl red solution were added to the culture and readings were taken immediately.

- Catalase test: A loopful of the culture was placed on a slide and few drops of $10 \%$ hydrogen peroxide were added. The slides were observed for effervescence.

n Screening: The lactic acid bacteria were screened for the production of Lactobacillus plantarum1 and Lactobacillus pentosus using Bergey's manual of determinative bacteriology (API - 50 CHL, BioMcricux). The identity of the cultures was based on the characteristics of the lactobacilli as described in Bergey's Manual of Determinative Bacteriology (Azcarate-Peril), fermentation of different carbon sources (API 50 ( HL, BioMérieux). The results form a biochemical profile which, when entered in the identification software, provides the identification of Lactobacillus plantarum1 and Lactobacillus pentosus

\section{Results and Discussion}

Bacteria isolated from the foregut, midgut and hindgut of Chrysichthys nigrodigitatus were identified as Lactobacillus plantarum I, Lactobacillus pentosus by obscrving their colony morphology, physiological and as well as some biochemical characteristics. Microscopically they were Gram-positive, rod shaped, non- motile, catalase negative and absence of Endospore Plate land 2. Lactobacillus plantarum 1 had the highest identification value of $99.9 \%$ as the significant taxa and Lactobacillus pentosus as the next taxon with identification value of $0.1 \%$ as represented in table 1 . The result obtained indicated a high accuracy of Chrysichthys nigrodigitatus probiotics. The strain was isolated from fish gut and was identified as Lactobacillus plantarum l by both biochemical test and $\Lambda$ PI 50CHL (Biomerieux). Corr et al. (2007) reported that bacteriocin producing LAB can effectively suppressed the growth of Listeria monocylogenes in fish and to eradicate its presenec. Sereening of these probiotics is required in order to develop probiotic bacteria with divers' antimicrobial potentials.

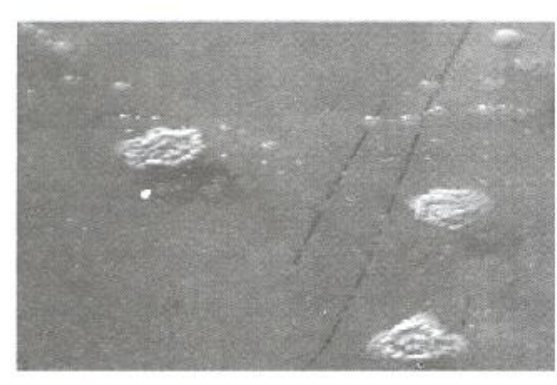

Plate 1: Non-spore forming Lactobacillus plantarum.

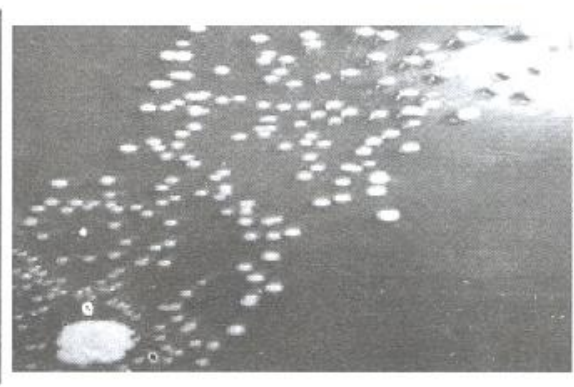

Plate 2: Colonies of Lactobacillus sp. 
Table 1: Summary of the result of isolation and identification of probiotics from fish gut (foregut, midgut and hindgut).

\begin{tabular}{l|ll|l|l|l|l|l|l|l}
\hline & \multicolumn{2}{c|}{ Probiotics } & & \multicolumn{3}{c|}{ Concentration } & \%ID & $\%$ ID & Result \\
\hline Fish Species & Sig. taxa & Next taxon & $\begin{array}{l}\text { Fore } \\
\text { gut }\end{array}$ & $\begin{array}{l}\text { Mid } \\
\text { gut }\end{array}$ & hindgut & Sig. taxa & Next taxa & \\
C. nigrodigitatus & L. plantarum 1 & L. pentosus & ++ & +++ & +++ & 99.9 & 0.1 & Excellent ID \\
\hline
\end{tabular}

Keys: ID - Idenifiation, +1 - Less alhundance, ++- More abundarice. Sig.- significance

\section{Conclusion}

Probistics isolated and sereened using an appropriate medium could be used as growth promoters in aquaculture production and could be administered in such a way to enter the gastrointestinal tract, to be kept alive and with the aim of improving health.

\section{REFERENCES}

Corr, S.C.; Li, Y.; Riedel, C.U.; O'Toole, P.W; Hill, C. and Gahan, C. G. 2007. Bacteriocin production as a mechanism for the antiinfective activity of Lactobacilus salivarius UCC1 18. Proc Nati Acad Sci. L.S.A. 104: 7617-7621.

Fuller, R. 1992. Probiotics: The scientifie basis. Chapman \& Hali, London, 398.

1989. Probiotics in man and animals: $\Lambda$ review. Joumal of Appied Bacteriology. 66: 365-378.

Ilassan, A.N. and. Frank. J.F (2001). Starter cultures and their use, In, E.II. Marth and J.L. Stecle (eds). Applied Dairy Microbiology, 2ni edition. Marcel Dekker; Inc, New York. 151-206.

Havenaar, R. and Iluis in't Veld, J.H.J. (1992a). Probiotics: a general view. In: The Lactic Acid Bacteria (Wood, B.J., Ed.), Vol. 1. The

Lactic Acid Bacteria in Health and Disease. Elsevier Applied Science. Londan. 151-170.

Saavedra, J.M. (2001). Clinical applications of probiotic agents. Amer. J. Clin. Nutr. 73: 11475-1151S.

Sullivan, M.G.O.; Thomton, G.; Sullivan, G.C.O. and Collins, J.K. (1992). Prohiotic bacteria: myth or teality? Trends food Sci. Technol. 3: $309-314$. 